\title{
Apuntes históricos sobre el manejo de la infección en el desarrollo de la cirugía
}

\author{
Enrique Laval $R$.
}

Pontificia Universidad Católica De Chile. Facultad de Medicina Programa de Estudios Médicos Humanísticos.

Recibido: 10 de marzo de 2010 Aceptado: 16 de abril de 2010

Correspondencia a: Enrique Laval Román

\section{Historical notes on the management of infection during the development of surgery}

Surgery and medicine have not evolved in parallel. There have been discrepancies, bellicosity, contempt and even separate university studies during a long time. The Saint Cosme Brotherhood, founded to supervise the professional practice of barbers (short robe surgeon-barbers) in France in 1260, was opposed by the Faculty of Medicine in Paris. The conflicting interests of the university, Brotherhood and Barbers, that persisted until the 18 th century, impaired the progress of surgery. In the first half of the 19 th century, the advance of surgery continued facing pain, hemorrhage and infection. The control of the latter had to consider antisepsis, asepsis and finally the appearance of antimicrobial substances, sulfonamides and antibiotics that allowed surgeons to approach and solve major problems of the specialty.

Key words: infection, antisepsis, asepsis antimicrobial agents.

Palabras clave: Infección, antisepsia, asepsia, antimicrobianos.
La "guerra" de los médicos contra los cirujanos. La cofradía de San Cosme

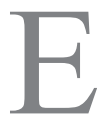
1 desarrollo de la cirugía nunca marchó paralelo al de la medicina; al contrario, estuvo caracterizado por un ritmo lento e irregular. A este caminar se sumó el entredicho secular entre médicos y cirujanos.

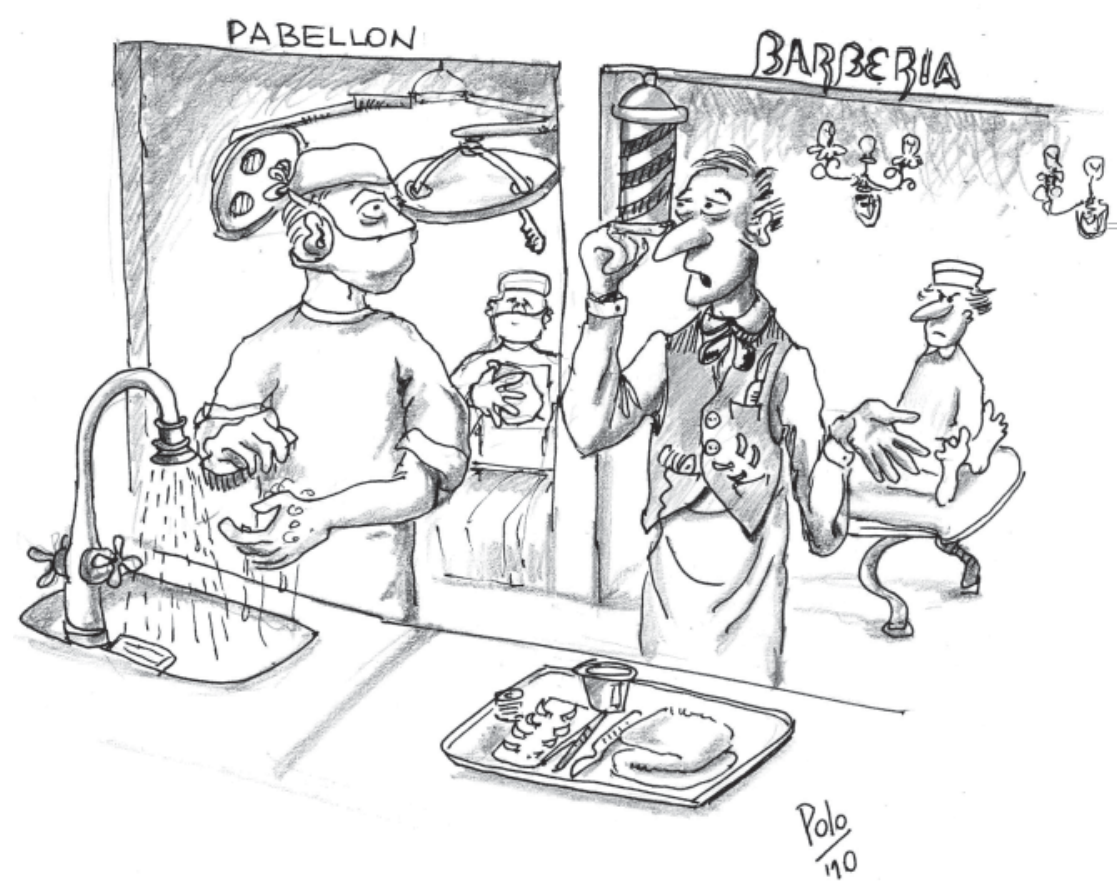

La Cirugía no había vivido solamente divorciada de la Medicina sino en beligerancia; los cirujanos no eran menospreciados, siendo en realidad despreciados, confundidos con los barberos.

En el año 1260 fue fundada la pequeña cofradía de San Cosme, compuesta por cirujanos y a comienzos del siglo XIV, se organizó y obtuvo el derecho de supervigilar el ejercicio profesional de los barberos. Poco a poco fueron agregándose nuevas atribuciones hasta convertirse en una verdadera Facultad paralela a la de Medicina de París, pues enseñaba cirugía y concedía título de Bachiller, Licenciado y Maestro.

No obstante, los barberos, más numerosos y disfrutando de la influencia del barbero del Rey, continuaron practicando la cirugía con la mayor amplitud.

Por su parte, la Facultad de Medicina de París, integrante de la Universidad, no quiso renunciar a sus derechos sobre barberos y cirujanos, oponiéndose a la extensión de los privilegios concedidos a la cofradía de San Cosme.

Luis XV reorganizó la Cofradía en 1724, fundando la Real Academia de Cirugía en 1735. Sin embargo, Federico el Grande en 1771, mediante un decreto autorizaba todavía "a cuidar las heridas a gentes sin título".

Todos estos intereses antagónicos de la Universidad, cofradía y barberos, duraron prácticamente hasta fines del siglo XVIII y ejercieron una influencia dañina sobre el desarrollo y evolución de la cirugía, lo que desencadenó una lucha prolongada, desapacible y estéril. Si hubo periódicas treguas, los odios fermentaban sordamente transmitiéndose de una generación a otra. 
España no escapó ciertamente a las limitaciones y luchas de la época. Se ha señalado, entre otros, un pequeño y curioso detalle que revela con intensa fuerza objetiva la diferencia que se hacía en Indias entre un médico y un cirujano. Al finalizar el siglo XVI el virrey del Perú, Marqués de Cañete, dictó una ordenanza sobre la "ración ordinaria que se ha de dar en las naves de la Armada de Su Majestad" y en ella se leía que al tratar de la cantidad de vino suministrada a la oficialidad, el Teniente General recibía cuatro botijas al mes, el Almirante tres, los Capitanes dos, el Capellán y el Médico una y el Cirujano ninguna". No se ha podido establecer con certeza cuál es la capacidad de una botija, pero evidentemente no debió ser escasa cuando el capellán y el médico no reclamaron que se les brindaba una al mes.

Durante mucho tiempo los estudios de Medicina se cursaban separados de los de Cirugía. Desde 1617 existían dos categorías de cirujanos: latinos o de toga larga y romancistas o cirujanos-barberos o de toga corta. Los latinos para ser aprobados tenían que demostrar su conocimiento de las obras hipocráticas, de Galeno, Guido y otros autores, que estudiaban durante cuatro años en latín en las Universidades y además, ser examinados de algebristas, esto es, en las enfermedades de los huesos y articulaciones, aprendidas en otros dos años. El todo formaba un conjunto de conocimientos más extensos y difíciles que los exigidos a los médicos. De aquí que los bachilleres optaran por la medicina y los cirujanos latinos fueron insensiblemente desapareciendo. Los romancistas carecían de estudios universitarios, eran meros prácticos formados en los hospitales o al lado de algún cirujano latino y debían rendir exámenes ante las autoridades respectivas ${ }^{1-3}$.

\section{Las barreras superadas por la llamada \\ "revolución quirúrgica": el dolor, la hemorragia y la infección. El "pus laudabilis" de Galeno}

En la primera mitad del siglo XIX, la mentalidad anátomo-clínica estimuló de forma decisiva el desarrollo de la patología y clínica quirúrgica, uniéndose al progreso del diagnóstico, el de la técnica quirúrgica en la línea iniciada anteriormente.

Sin embargo, los resultados prácticos distaban mucho de ser satisfactorios, con tasas de mortalidad post-operatoria elevadas, porque los cirujanos del periodo anátomo-clínico, así como los de todas las épocas, tenían que enfrentarse con las tres barreras que más tarde superó la llamada "revolución quirúrgica": el dolor, la hemorragia y la infección.

Recordemos que la cirugía de los primeros siglos no fue más allá de la curación de las heridas, apertura de abscesos, extracción de aquellos cuerpos extraños fácilmente accesibles, sangrías y en los pueblos primitivos, con profundo sentido religioso, la trepanación del cráneo ${ }^{3}$.
Hipócrates (460-370 AC) pudo haber sido el primero en opinar sobre las supuraciones, afirmando que la formación de pus no era un componente natural en el proceso de curación y cicatrización, debiendo ser evitado. Sus recomendaciones para el tratamiento de las heridas, similares a las preconizadas anteriormente por los sumerios, eran: limpieza con vino, aplicación de vendaje, sobre el que también debía verterse vino.

Claudio Galeno (130-200 DC), el cirujano de los gladiadores de Pérgamo, estableció conceptos y doctrinas que fueron indiscutibles durante 15 siglos, constituyendo normas en la práctica médica. Muchos de sus juicios y opiniones probaron ser verdaderos, pero no obstante uno muy importante, desgraciadamente incorrecto: "que la formación de pus era esencial para la curación de las heridas", lo que fue conocido como el "pus laudabilis", atrasando el progreso de la cirugía hasta le época de Lister.

Entre los que desafiaron el concepto galénico de la supuración, vale la pena mencionar a Henri de Mondeville (1205-1298), formado en la Universidad de Montpellier y a Teodorico Borgononi que rechazó con énfasis todo lo concerniente al "pus laudabilis", planteando medidas esenciales en el manejo de las heridas, entre ellas la remoción del material contaminado o necrótico. Como sus afirmaciones estaban en completa oposición a le establecido por Galeno, fue denunciado por sus colegas a la Iglesia.

La doctrina de la supuración de Galeno continuaría siendo la norma hasta el siglo XIX.

Ambrosio Paré (1510-1590), considerado uno de los padres de la cirugía moderna, sostuvo que la infección era introducida desde el ambiente, por lo que varios destacaron la importancia de un medio ambiente estéril, para prevenir la transmisión de la enfermedad.

Antonio van Leeuwenhoeck (1632-1723), "pionero de la microbiología", fue el primero en distinguir las bacterias, publicando sus dibujos en 1683. Logró fabricar más de 200 microscopios compuestos, estudiando la putrefacción tres siglos antes de Pasteur.

Bernard Gaspard (1788-1871), en importantes experimentos sobre la putrefacción, a partir de 1808, pero no publicados hasta 1822 , demostró que la sangre de un perro que padeciera una "intoxicación pútrida" podía ocasionar idénticos síntomas una vez inyectada a otro perro. Magendie en 1823, comprobó que la sangre pútrida no es tóxica por vía digestiva y que su toxicidad disminuye al filtrarla ${ }^{1,2,4}$.

\section{Iniciación de la Microbiología Médica: Davaine y Pasteur. Antisepsia y Asepsia: Lister y Semmelweiss}

Si bien con Casimir Joseph Davaine (1812-1862) se inicia en realidad la verdadera microbiología médica, con sus investigaciones sobre el carbunco, sería la aparición 
en escena de Luis Pasteur (1822-1895), con sus colaboradores franceses y los microbiólogos alemanes, ingleses, italianos, etc. los que harían progresar aceleradamente los conocimientos bacteriológicos. Pasteur destruyó el mito de la generación espontánea, atribuyendo la fermentación y putrefacción de la carne a organismos vivos. Tanto la simplicidad como la racionalidad de sus experimentos llevarían a sus contemporáneos a adoptar la teoría de los gérmenes. Su aislamiento y cultivo, junto al estudio anátomo-clínico de muchas enfermedades, permitiría diferenciarlas y caracterizarlas definitivamente ${ }^{1}$.

José Lister (1827-1912), profesor de Cirugía en Glasgow, sería el primero en comprender la conexión entre el descubrimiento de Pasteur del proceso de putrefacción y la supuración de las heridas, llevándolo a pensar que "si son gérmenes microscópicos los que producen la descomposición de las heridas, evitémoslos o destruyámoslos". Había nacido la antisepsia. El método de Lister con la utilización del ácido carbólico o fénico revolucionaría la cirugía, mejorando sustancialmente el resultado post operatorio de las intervenciones, disminuyendo las complicaciones supurativas. En Francia, el célebre cirujano Champonnière luchaba con fervor de apóstol para difundir el método listeriano, anotando que "todo lo que podré decir, es que no he tenido un solo caso de complicación de herida, no he visto ni erisipela ni infección purulenta y he practicado operaciones que antes no se usaban en Francia". Durante su estadía en dicho país, el doctor Manuel Barros Borgoño trabajó con aquel cirujano, aprendiendo la técnica antiséptica y después fue el primero en implantarla en Chile. Junto con Francisco Puelma Tupper, Vicente Izquierdo y Máximo Cienfuegos, formaron el primer grupo de becados que concurrieron a las principales clínicas francesas, inglesas y alemanas, enviados por el Gobierno de Chile en 1874, para estudiar los progresos médicos y quirúrgicos más recientes.

Alberto Cristián Teodoro Billroth (1829-1894), uno de los más grandes profesores e innovadores de la cirugía, no creía que las bacterias eran importantes en la infección de las heridas, pero estuvo dispuesto a utilizar el sistema listeriano después de comprobar que producía buenos resultados.

No corresponde referirse, en esta oportunidad, a los extraordinarios aportes que hizo Billroth al diagnóstico quirúrgico y a las técnicas operatorias. Pero si mencionar su afán por encontrar la sustancia productora de la fiebre en sus investigaciones en el pus, la que como pirógeno endógeno, bien pudo corresponder al humor bilioso de la Escuela Hipocrática o a la acrimonia de Silvio, a la pirexina de Menkin y mucho más reciente a la interleukina-1 ${ }^{5-7,9}$.

Precediendo a Pasteur y Lister, en 1843, Oliver Wendell Holmes (1809-1894) intentando evitar los procesos de contaminación e infección, sugirió que la fiebre puerperal fetal era contagiosa y que podía prevenirse con el lavado de manos y cambio de ropa de los doctores, argumento que ocasionó ofensa entre sus pares, considerándose una crítica a la higiene personal de los médicos.

Cuatro años después, el médico húngaro Ignaz Semmelweiss (1818-1865), logró descubrir la naturaleza infecciosa de la fiebre puerperal e independientemente de Holmes dijo lo mismo, al observar en la Maternidad del Hospital de Viena, que las mujeres atendidas por las matronas y que se lavaban las manos, tenían una mortalidad menos a causa de esta infección, que aquellas que lo eran por estudiantes de Medicina, previa práctica en anatomía patológica y que no se las lavaban. Introdujo la desinfección de las manos mediante lavado con una solución de cloro, en forma obligatoria para médicos, estudiantes y personal del servicio hospitalario, disminuyendo la letalidad de la infección puerperal desde casi 10 a $1,3 \%$, en dos años.

Sin embargo, tanto las observaciones de Holmes como las de Semmelweiss, encontraron una fría acogida en la comunicad médica, En todo caso había nacido el concepto de asepsia.

En 1891, perfeccionándose en las prácticas listerianas, Ernst von Bergmann preconizó la esterilización del instrumental quirúrgico por el calor, que probó ser mejor que la química. Gustavo Neuber en 1893, introdujo los delantales y gorros estériles; Mikulicz en 1897, las mascarillas. El uso de los guantes de goma se produjo después de 1890, cuando William Stewart (1852-1922) solicitó a la Compañía Goodyear, fabricarlos para sus enfermeras, con el fin de protegerles las manos de las soluciones de sublimado para la desinfección de los instrumentos ${ }^{1}$.

En 1948, el doctor Adolfo Reccius escribía: "el ritual de la asepsia, es hoy día el mismo en todo el mundo. Poco a poco fue desalojando a la antisepsia de Lister y junto con el advenimiento de ella, ha ido cambiando el aspecto exterior del cirujano y de sus ayudantes. La indumentaria rigurosa del médico y cirujano de antaño, la levita o el chaquet ha cedido el paso al delantal blanco, la gorra, mascarilla y los guantes esterilizados, cumpliendo con lo que Billroth había exigido ya hace más de medio siglo: limpieza hasta la exageración"?.

De nuevo destacamos que la infección ha sido uno de los grandes problemas que ha enfrentado la cirugía, desde su aparición en la historia. El temor a ella impidió el desarrollo quirúrgico, hasta que en la segunda mitad del siglo XIX, Lister aplicó los principios de Pasteur 5 .

Citando a Sergio de Tezanos Pinto podemos decir que en forma muy acertada el siglo XIX ha sido llamado el "siglo de los cirujanos".

La bacteriología, ciencia pre-clínica, se proyectó sobre toda la medicina, pero su aplicación práctica a la cirugía, por medio de la antisepsia, le permitió a ésta elevarse al plano que tanto necesitaba, ya que la anestesia había permitido actuar tranquilamente al cirujano ${ }^{4}$. 
Según Lucas Sierra "fue muy sensible que el descubrimiento de la anestesia (1842-47), hubiera precedido en tantos años al de la antisepsia (1865-78)"”.

Aparición de las sustancias antimicrobianas: sulfamidados y antibióticos. Controversia por su utilización con fines profilácticos. El dilema "rapidez o lentitud" en el acto quirúrgico

Casi paralelo al incesante progreso de la microbiología, con el conocimiento del poder patógeno de los gérmenes, a través de estudios más acabados sobre la virulencia y de nuevas especies microbianas, de los avances de la genética molecular, en las últimas décadas, que han llevado a una comprensión mejor del programa genético de los microorganismos, asistimos desde los años 30 a la aparición de sustancias antimicrobianas, con los sulfamidados, después con los antibióticos, inicialmente la penicilina, luego la estreptomicina, tetraciclina, cloranfenicol y sin detenerse hasta hoy, aminoglucósidos, vancomicina, cefalosporinas, quinolonas, etc, que han sido importantísimos en la terapéutica quirúrgica y algunos en el ámbito profiláctico. Junto con el progreso de las técnicas quirúrgicas, de la anestesia y de otras medidas de soporte, han permitido a los cirujanos intervenciones torácicas (pulmonares y cardiacas), abdominales, intracraneales, trasplantes, etc. jamás soñados en épocas anteriores.

Si bien la llegada de los antibióticos pareció terminar con las preocupaciones por la infección, el tiempo ha demostrado que la cirugía sigue como un medio terapéutico y efectivo y que estos fármacos tienen sus limitaciones.

Hay ciertos límites y desinformaciones que aún persisten: se ha presentado la infección quirúrgica como nosocomial, olvidando que cerca de $30 \%$ se inicia en la comunidad; se habla casi exclusivamente de la infección de la herida operatoria, sin referirse a otras complicaciones sépticas, que pueden alcanzar mayor significación.

No se reconoce lo suficiente el papel del propio paciente como reservorio de gérmenes patógenos, olvidándose las infecciones no bacterianas, por hongos o por virus, que pueden irrumpir en un paciente operado inmunodeprimido.

A veces se deposita excesiva confianza en los antibióticos, olvidando que sólo facilitan y dan tiempo a los propios sistemas defensivos.

El objetivo de la profilaxis antibiótica en cirugía, consiste en disminuir la carga bacteriana cuando comienza el daño quirúrgico, lo que ha demostrado reducir la incidencia de infección del sitio operatorio, abarcando desde la piel hasta cualquier parénquima o cavidad anatómica.

Lo más importante de la bacteriología de las infecciones quirúrgicas en los últimos decenios fue la alta frecuencia de Staphylococcus aureus; al aumento impresionante entre 1985 y 1995 de infecciones severas de tejidos blandos, sobre todo de fascitis necrosante, producidas por Streptococcus pyogenes ( $\beta$-hemolítico del grupo A), en que fue muy relevante, además de la terapia antibiótica, la acción quirúrgica agresiva; los bacilos gramnegativo, en especial enterobacterias; el aumento de las infecciones polimicrobianas y de bacilos anaerobios, esporulados y no esporulados.

Cabe mencionar que los antimicrobianos son coadyuvantes del sistema inmune. Así, en un paciente desnutrido o diabético descompensado, el riesgo de infección es mayor independiente del antibiótico, por lo que la corrección de todos los factores pre-operatorios es crucial para obtener buenos resultados ${ }^{9-14}$.

Pareciera que no todo está resuelto en la utilización de antibióticos con fines profilácticos, siendo exagerada para algunos y con frecuencia incorrecta, asegurando de que a pesar de su gran aceptación, no se ha confirmado su eficacia en numerosas intervenciones o al menos es motivo de controversia.

Se ha dicho que la descripción del estado actual de la cirugía, podría ser reducida de un modo esquemático, a algunos puntos, uno de los cuales sería la conquista paulatina del "factor tiempo". La introducción de la anestesia no quitó el hábito de operar con la rapidez máxima, aun cuando tras la instauración de la cirugía aséptica se supiera que la manipulación delicada y cuidadosa de los tejidos disminuye el riesgo de infección. Doyen, en el París de comienzo del siglo XX, Albert Aston Berg y John Erdenan, en Nueva York en 1917, seguían proclamando las ventajas de la cirugía rápida, porque - decían - si la lenta delicadeza de la mano quirúrgica rebaja el peligro de la infección, la prolongación del acto operatorio hace que el campo se halle más tiempo expuesto a los posibles agentes contaminantes. Por lo tanto dos escuelas: la de la rapidez a ultranza y la de la lentitud.

En rigor el dilema "rapidez o lentitud" debe ser resuelto teniendo en cuenta dos normas básicas: que el fin primero del cirujano es la curación del enfermo y que la operación para ser correcta debe atenerse a una serie de principios fundamentales. "La máxima perfección con la mayor rapidez"; tal es la regla óptima y tal parece ser la actitud hoy dominante ${ }^{14,15}$.

Finalmente, creo conveniente considerar lo que en alguna oportunidad escribió el importante neurofisiólogo y neurocirujano Harvey Cushing (1869-1939): “ciertamente no todas las infecciones se deben a la mala suerte o al demonio, sino también pueden ser responsabilidad de los doctores"3.

\section{Resumen}

La cirugía y la medicina no evolucionaron en forma paralela, con discrepancias, reservas, belicosidad, despre- 
cios e incluso estudios universitarios separados durante bastante tiempo. La Cofradía de San Cosme, fundada en Francia en 1260, para supervigilar el ejercicio profesional quirúrgico de los barberos (cirujanos-barberos de toga corta), tuvo la oposición de la Facultad de Medicina de París. Los intereses contrapuestos de la universidad, Cofradía y Barberos, que persistieron hasta fines del siglo XVIII, perjudicaron el progreso de la cirugía. En la primera mitad del siglo XIX, el avance de la cirugía continuó enfrentándose al dolor, la hemorragia y a la infección. El control de ésta debió pasar por la antisepsia, asepsia y finalmente por la aparición de las sustancias antimicrobianas, sulfamidados y antibióticos, que permitirían a los cirujanos abordar y solucionar problemas de mayor relevancia de la especialidad, curativos y preventivos.

\section{Referencias}

1.- Laval M E. Historia de las grandes etapas de la cirugía en Chile. An Chil Hist Med 2006;16: 243-62.

2.- Laval M E. Normas para el ejercicio de la Medicina y de la Cirugía en España y América en los siglos XVI al XVIII. En noticias sobre los médicos en Chile. Siglos XVI a XIX (A-B). Ed. Historia Médica. Santiago de Chile. 1970.

3.- Bynum W F, Porter R. Companion Encyclopedia of the History of Medicine. Vol. I. Routledge, New York, London.
1993.

4.- De Tezanos Pinto S. Breve Historia de la Medicina Universal y notas sobre la Medicina Chilena. Ed. Universitaria. Santiago de Chile. 1979.

5.- Laval R E. El método antiséptico de Lister y su introducción en Chile. Rev Chil Infect 2001; 18: 215-21.

6.- Laval R E. Fiebre. Rev Chil Infect 1987; 4: 29-32.

7.- Reccius E A. Historia y desarrollo de la cirugía abdominal en Chile. Ed. Zig-Zag, S.A. Santiago de Chile. 1948.

8.- Sierra M L. Cien años de la enseñanza de la medicina en Chile. Santiago de Chile. 1934.

9.- Reccius E A. Historia de la Cirugía Toráxica en Chile. Impta. y Lit Universo. Valparaíso, Chile. 1957.

10.- Pérez A P, Del Solar H F, Pomes G J, Bastías R J, Croquevielle P J, Aulufi C, et al. Infección quirúrgica. Rev Chil Cir 1987; 38: 75-81.

11.- Paredes P L. Antibióticos en Cirugía. Rev Chil Cir 1965; 17: 582-97.

12.- Soto R E. Antibióticos en Cirugía. Rev Chil Cir 1965; 17 : 597-604.

13.- Vigueira Casal J B. Antibióticos en Cirugía. Aspectos clínico-quirúrgicos. Rev Chil Cir 1965; 17: 604-12.

14.- Dujovich R E, Sapisochin E, Beresten,S. Antibióticos en el post-operatorio de las laparotomías. Rev Chil Cir 1965; 17 : 612-4.

15.- Mandell G L, Douglas R G, Bennett J E. Enfermedades infecciosas. Infecciones post-quirúrgicas y profilaxis antimicrobiana. Vol. II. Ed. Médica Panamericana. Buenos Aires, Rep. Argentina. $3^{\text {a }}$. Ed. 1992. 